\title{
A análise da atenção domiciliar no âmbito da reabilitação no Sistema Único de Saúde de Belo Horizonte a partir de casos traçadores
}

Jane Fonseca Dias, Júlia Baldoni Grossi, Sheyla Rossana Cavalcanti Furtado, Rosana Ferreira Sampaio

\section{Resumo}

A Atenção Domiciliar (AD) foi redefinida pela portaria de $n^{\circ}$ 963, de 27 de maio de 2013, como uma modalidade de atenção à saúde, substitutiva ou complementar às já existentes, caracterizada por um conjunto de ações de promoção, prevenção e tratamento de doenças e reabilitação prestada em domicílio, com garantia de continuidade de cuidados e integrada às redes de atenção à saúde. Independente da denominação recebida e da sobreposição de conceitos, a AD envolve a disponibilidade de equipes multiprofissionais e a articulação com a rede. Sendo assim, os serviços de reabilitação e os profissionais não devem ser vistos, e nem atuar, como peças isoladas dessa rede de cuidado. A organização da AD prioriza o atendimento compartilhado e interdisciplinar, com trocas de saberes e responsabilidade mútua. Nesse contexto, a AD traz a expectativa de proporcionar mudanças significativas no atual modelo tecnoassistencial. O presente estudo teve como objetivo analisar a organização da atenção domiciliar no âmbito da reabilitação e o acesso do usuário a essa prática e à rede de saúde, a partir do ato de cuidar. Trata-se de pesquisa qualitativa com acompanhamento de casos traçadores, permitindo conhecer como se concretizam na prática processos de trabalho complexos como o da AD. A coleta de dados ocorreu no território de abrangência do distrito nordeste da cidade de Belo Horizonte no período de junho de 2015 a janeiro de 2016 a partir da busca na Atenção Básica por casos prospectivos e retrospectivos reconhecidos pela equipe como de alta complexidade, ou seja, aqueles que exigiam a mobilização de distintos serviços e saberes. A amostra foi composta de cinco casos traçadores pertencentes a três Centros de Saúde, envolvendo quatro ESF e dois pólos de NASF de referência. A análise documental, a observação e as entrevistas propiciaram a construção e a análise de um traçado do percurso e do acesso à rede de cuidado, a partir das relações criadas entre usuários, profissionais e comunidade. $\mathrm{O}$ Sistema oferece serviços que prestam $\mathrm{AD}$ nos três componentes da rede: atenção básica, especializada e urgência e emergencia. Foram observados traçados desordenados e itinerários imprevisíveis com surpreendente quantidade de serviços e equipes mobilizadas para o cuidado e impulsionados por ações e reações ao sistema (potências e ineficiências). Independentemente de onde o usuário deu entrada no sistema ele iniciou sua rede de relações, não havendo necessidade de estabelecer previamente um centro coordenador. Esse desenho esteve ancorado na existência de múltiplas redes de cuidado, que se entrelaçam e se afetam mutuamente, envolvendo sistemas dinâmicos e favorecendo a construção de redes formais e redes informais de cuidado. As ações desenvolvidas informalmente deveriam ser consideradas com mais atenção, pois carregam um potencial generoso para transformar o modo de pensar e fazer em saúde, configurando um modelo de saúde no qual a demanda do usuário e da família passa a ser preponderante.

Descritores: Reabilitação; Atenção Domiciliar; Sistema Único de Saúde. 